\title{
Oral Liposomal Iron: A Treatment Proposal for Anemia
}

\author{
1 Jaideep Malhotra, ${ }^{2}$ Ruchika Garg, ${ }^{3}$ Narendra Malhotra, ${ }^{4}$ Prabhat Agrawal
}

How to cite this article: Malhotra J, Garg R, Malhotra N, Agrawal P. Oral Liposomal Iron: A Treatment Proposal for Anemia. World J Anemia 2017;1(4):1-6.

\section{Source of support: Nil}

\section{Conflict of interest: None}

\section{ANEMIA AND TREATMENT OPTIONS}

Anemia is a public health problem affecting about a third of the world's population both in developing and in developed countries. It is known to occur at all stages of life; children aged 0 to 5 years, women of childbearing age, and pregnant women are particularly at risk. According to the World Health Organization report, $50 \%$ of all cases of anemia is due to iron deficiency. ${ }^{1,2}$ The prevalence of any type of anemia is very high ( $>95 \%$ ) among children, adolescents, and pregnant women in India. ${ }^{3}$ The main risk factors for iron deficiency anemia (IDA) are: Low iron intake, different levels of chronic blood loss, and malabsorption. In addition, certain chronic diseases like chronic kidney disease (CKD), chronic heart failure, cancer, and inflammatory bowel disease (IBD) are frequently associated with IDA. ${ }^{2,4}$ Iron deficiency anemia is also known to affect a large part of adult and elderly patients in internal medicine units. ${ }^{5}$ Treatment strategies encompass prevention, to normalize hemoglobin $(\mathrm{Hb})$ levels and Wintrobe indices and prompt iron replacement plus diagnostic steps directed toward correcting the underlying cause of IDA. ${ }^{1,2,6}$

Oral iron is usually recommended as first-line therapy, as it is a cost-effective strategy to restore iron balance. Both ferrous and ferric forms are available, but only the ferrous form is recommended due to superior absorption. Ferrous sulfate is used most frequently, but ferrous gluconate and fumarate can also be used..$^{1,2,7}$

\footnotetext{
${ }^{1,3}$ Consultant, ${ }^{2,4}$ Associate Professor

${ }^{1,3}$ Rainbow IVF, Agra, Uttar Pradesh, India

${ }^{2}$ Department of Obstetrics and Gynecology, Sarojini Naidu Medical College, Agra, Uttar Pradesh, India

${ }^{4}$ Department of Medicine, Sarojini Naidu Medical College, Agra Uttar Pradesh, India
}

Corresponding Author: Jaideep Malhotra, Consultant, Rainbow IVF, Agra, Uttar Pradesh, India, e-mail: jaideepmalhotraagra@ gmail.com
Shortcomings of oral iron supplementation are: (1) Poor iron absorption (10-15\%), (2) iron loss or iron requirements in excess of the absorbed dose, (3) low bioavailability, (4) poor tolerability, (5) leading to noncompliance. Iron absorption can be lowered by concomitant intake of iron absorption inhibitors like phosphates, phytates, and tanates in food and certain digestive disorders. Certain side effects like abdominal discomfort, nausea/ vomiting, diarrhea, and/or constipation are directly related to the amount of elemental iron ingested. ${ }^{1,6,8,9}$

Intravenous (IV) iron is recommended as second-line therapy for patients who do not respond to oral iron, who have intolerance to oral iron, or who are noncompliant with oral iron therapy, require rapid iron replacement, malabsorption due to surgery, heavy bleeding, concomitant use of erythropoietin, and anemia secondary to cancer or chemotherapy. ${ }^{1,10}$ Some of the IV preparations available are iron gluconate, iron hydroxide sucrose complex, and iron dextran. ${ }^{7}$ In spite of their good safety profiles, IV iron preparations are painful, require patient monitoring and carry the risk of anaphylaxis and certain preparations can cause injection site discoloration.,10

\section{LIPOSOMAL DRUG DELIVERY}

English hematologist Alec Bangham in 1961 first described the liposomes and since then they have been recognized and extensively used as delivery vehicles for pharmaceuticals. ${ }^{11}$

Liposomes are spherical vesicles characterized by a bilayer of lipids with an internal aqueous cavity. Liposome structural components are phospholipids or synthetic amphiphiles incorporated with sterols. This phospholipid bilayer is suitable for fundamental cellular functions, such as motility and shape change, and provides also the ability to mimic the biophysical properties of living cells (Fig. 1). Two delivery areas where liposomes have shown most promise are drug delivery and gene therapy, owing to the advantages that their use brings over traditional methods. In the area of drug, most liposomal drug formulations are approved for IV application; intramuscular and oral delivery have also been examined. Liposomes are biphasic and therefore render them the ability to act as carriers for both lipophilic and hydrophilic drugs. Encapsulation of drugs in liposomes enhanced the therapeutic indices of various agents, mainly through alterations in their pharmacokinetics and pharmacodynamics. ${ }^{12,13}$ 


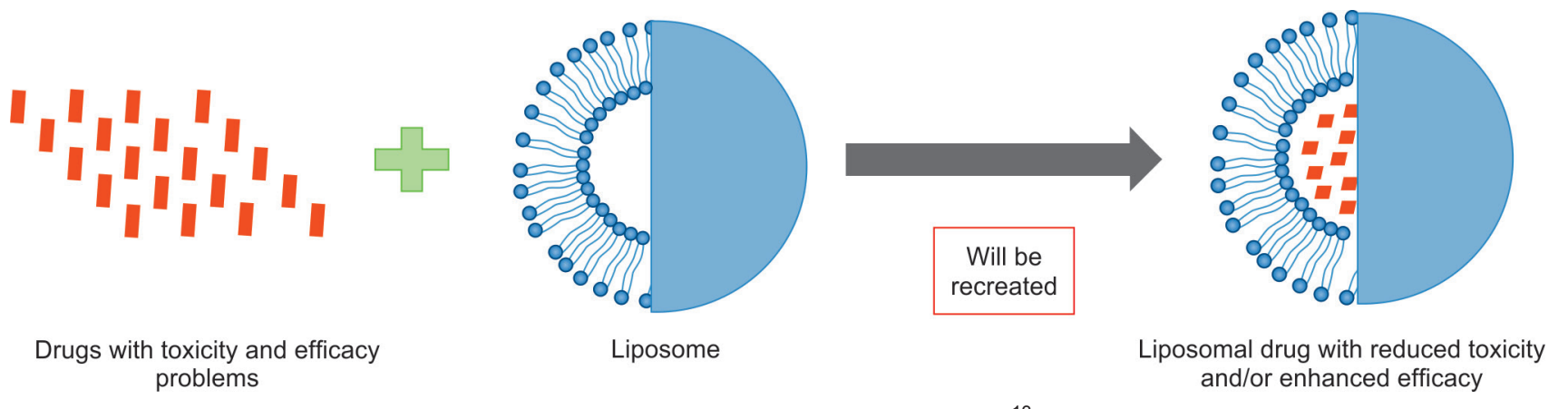

Fig. 1: Formulation of drugs in liposomes ${ }^{13}$

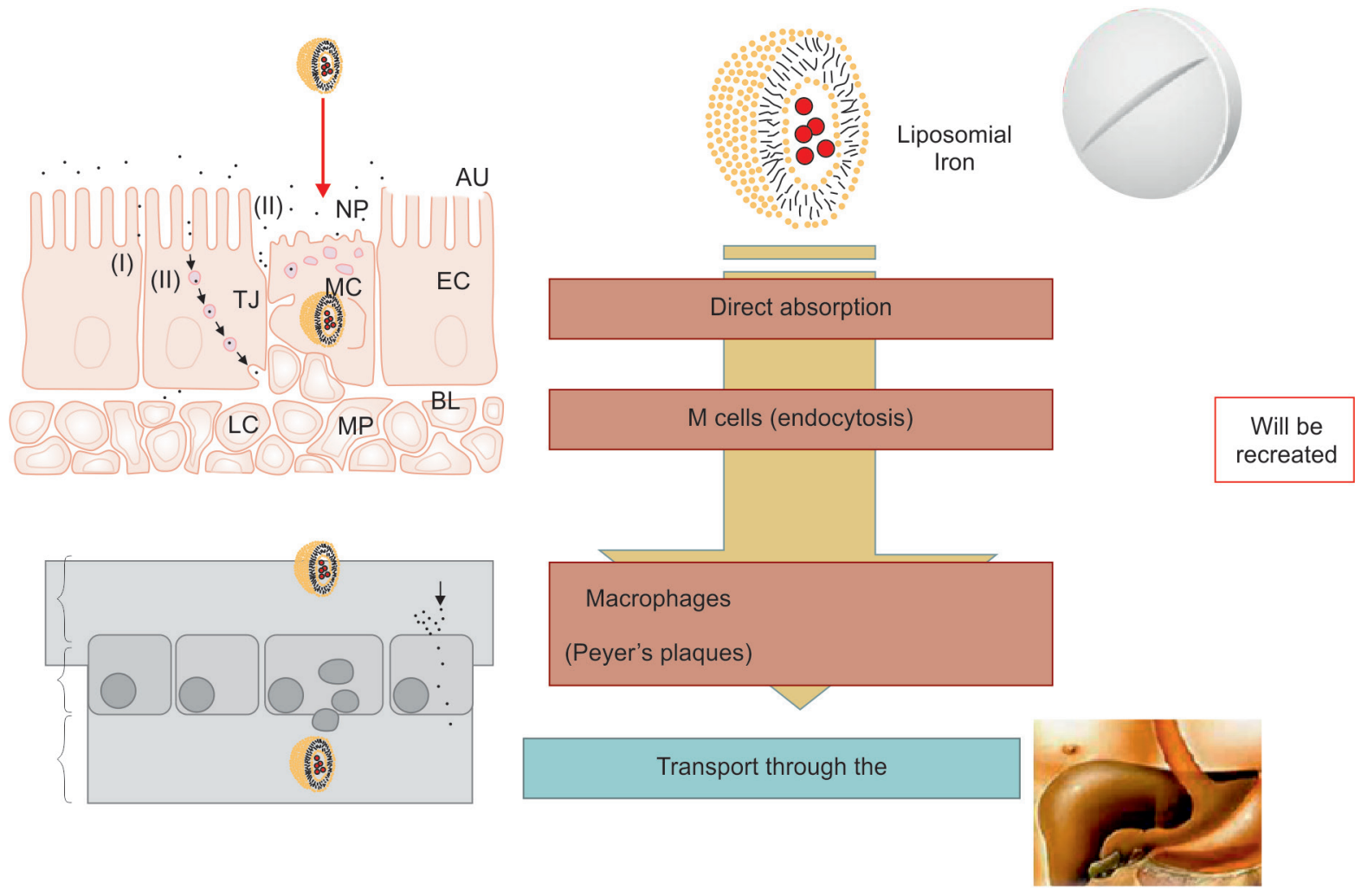

Fig. 2: Liposomal iron absorption ${ }^{14}$

The characteristics of the liposomes can be altered according to the different substances carried. For example, it can decrease the speed of degradation of the liposome and slow down the release of its content. The affinity of liposomes for a given tissue can be increased by varying its composition and electrical charge or even adding adhesive receptors or antigens. ${ }^{14}$

\section{ORAL LIPOSOMAL IRON}

Iron salts like ferrous pyrophosphate are covered with liposome, a spherical structure of a phospholipidic nature that is similar to those human cell membranes. This preparation crosses the gastric acid barrier and reaches the small intestine intact. In the intestine, the $\mathrm{M}$ cells due to their low lysozyme content integrally absorb liposomal iron without the need for specific transporters (Fig. 2).
Subsequently, the liposome is incorporated by endocytosis from macrophages and through the lymphatic stream it reaches, intact, the hepatocytes. The liposomal protection allows the iron to overcome the free gastric environment, preventing early degradation of the substance and / or its inactivation and to be absorbed directly. This mechanism provides liposomal iron a greater availability, reduces gastrointestinal side effects, and prevents iron instability in the gastrointestinal tract to be directly absorbed into the intestine and directly liberated into the liver. ${ }^{14-16}$

Consequently, this method of iron supplementation is associated with high gastrointestinal absorption, high bioavailability, and a low incidence of side effects. ${ }^{17}$ The absorption or bioavailability of liposomal pyrophosphate iron is 3.5 times greater than the free pyrophosphate iron, 2.7 times higher than iron sulfate, and 4.1 times higher 
compared with iron gluconate. In addition, the plasma concentration of liposomal iron was maximum after 2 hours from the assumption, which guarantees greater bioavailability of the element for all metabolic processes. ${ }^{14}$

However, the transportation of iron can be regulated by the size of liposomes, and it decreased with particle size increasing. Furthermore, depending on the size of liposome, different pathways, such as altering signaling processes essential for basic cell functions, receptormediated endocytosis, phagocytosis, rather than traditional absorption pathway can be taken up. ${ }^{18}$

In one of the comparative studies, absorption of liposomal ferrous glycinate was higher than ferrous glycinate and that inhibitory effects of phytic acid and zinc on iron absorption were reduced by incorporating ferrous glycinate into liposomes. For example, at the iron concentration of $50 \mu \mathrm{mol} / \mathrm{L}$, the iron transport at phytic acid concentration of $100,200,500$, and $1000 \mu \mathrm{mol} / \mathrm{L}$ was decreased by $3.0,4.6,7.4$, and $14.0 \%$ for ferrous glycinate liposomes and by $8.0,16.5,27.0$, and $45.2 \%$ for ferrous glycinate respectively. ${ }^{18,19}$ Liposomal iron has shown to be significantly more bioavailable than microencapsulated ferric pyrophosphate ingredients and ferrous sulfate in Caco-2 cell model. ${ }^{16}$

\section{CLINICAL USES}

\section{Chemotherapy-related Anemia}

Anemia in cancer patients is common due to pathologic deficiency in the amount of oxygen-carrying $\mathrm{Hb}$ in red blood cells. Current treatment for chemotherapyassociated anemia often relies on the use of erythropoieticstimulating agents. In one of the recent studies by Mafodda et $\mathrm{al}^{20}{ }^{20}$ a comparison between oral liposomal iron $v s$ IV iron in anemic cancer patients receiving chemotherapy was made. Liposomal oral iron provided similar increase in $\mathrm{Hb}$ levels and $\mathrm{Hb}$ response, with higher tolerability without the risks or side effects of IV iron. Similarly, from baseline to study end, a mean increase in $\mathrm{Hb}$ levels of $2.2 \mathrm{gm} / \mathrm{dL}$ and improvement in quality of life (QoL) parameters was noted with liposomal iron in patients with chemotherapyrelated anemia. ${ }^{21}$ Barni et $\mathrm{al}^{22}$ suggest that liposomal iron could be considered as a prophylactic measure to prevent transfusions/erythropoiesis-stimulating agents (ESAs) in cancer patients treated with chemotherapy and preexisting mild anemia.

Liposomal iron can be used as supportive therapy to reduce fatigue and improve QoL in patients with advanced prostate cancer and bone metastasis treated with monthly IV injections. It is also suggested that liposomal iron could be considered for its prophylactic use to prevent transfusion/ESAs in patients with preexisting mild anemia and to improve compliance at treatment with monthly IV injections of Radium-233 dichloride. ${ }^{23,24}$ In young advanced-stage Hodgkin lymphoma patients, supplementation of oral liposomal iron was well tolerated and maintained $\mathrm{Hb}$ above levels, requiring further supportive therapy. ${ }^{25}$

\section{Iron Deficiency Anemia and Inflammatory Bowel Disease}

A preliminary study showed that IDA and IBD patients on liposomal iron (10.5-12.4 gm/dL) had better increase in $\mathrm{Hb}$ levels as compared with patients on ferrous sulfate (10.8$11.7 \mathrm{gm} / \mathrm{dL}$ ) or no iron supplement (11.3-11.9 gm/dL). An increase of $\mathrm{Hb}>2 \mathrm{gm} / \mathrm{dL}$ was more frequent in patients treated with liposomal iron than in patients with no iron supplement. Liposomal iron was well tolerated in both IDA and IBD patients. ${ }^{26}$ In a similar study, one-third of the IBD patients treated with liposomal iron were normalized in 12 weeks, with an average $\mathrm{Hb}$ increase of 11.1 to 11.8 $\mathrm{gm} / \mathrm{dL}(\mathrm{p}=0.0023)$. Furthermore, the average rating in the questionnaire on QoL of IBD (CCVVEII-9) improved from 61.2 to 66.8 points on the final visit. An adherence of $>90 \%$ and acceptance of $>80 \%$ was noted. Therefore, liposomal iron can be helpful in those patients who do not tolerate classic prepared doses of oral iron. ${ }^{27}$ In refractory anemia, oral liposomal iron is found to safe, effective, and has demonstrated noninferiority over IV iron. ${ }^{28,29}$ Compared with conventional iron supplements like ferric ammonium citrate and heme iron, liposomal iron increased iron levels and $\mathrm{HB}$ concentrations so as to alleviate the anemia in murine models of sports anemia and anemia of inflammation. ${ }^{30}$ Liposomal iron was also effective in elderly patients, well tolerated, and produced a great improvement in the anemia condition without side effects, which helped in improving QoL. ${ }^{31}$ Liposomal iron was found to be more effective than iron sulfate in increasing $\mathrm{Hb}$ levels and to reduce inflammatory markers in correction of anemia of chronic inflammatory disease. ${ }^{32}$ The IBD patients are usually more frequently resistant to oral therapy and they show low compliance. Liposomal iron showed excellent compliance and treatment adherence. ${ }^{33}$

\section{Chronic Kidney Disease-related Anemia}

In the preliminary study, 21 patients with CKD-related anemia were analyzed, 14 of whom were treated with oral liposomal iron and 7 with IV iron. The observed increase of $\mathrm{Hb}$ at 8 weeks compared with baseline was similar in both groups, but was significant in the liposomal group only. ${ }^{14}$ Data show that oral iron administration compared with the IV iron therapy showed a significant increase in terms of $\mathrm{Hb}$ concentration and transferrin saturation and a significant decrease regarding C-reactive protein values and weekly consumption of erythropoietin. In conclusion, 
liposomal iron seems to be a valid alternative to IV iron therapy in CKD patients. ${ }^{34}$ A recent study by Pisani et al ${ }^{35}$ showed that oral liposomal iron was a safe and efficacious alternative to IV iron gluconate to correct IDA in nondialysis CKD patients. Oral liposomal iron was also effective in improving and or/maintaining $\mathrm{Hb}$ values in hemodialysis patients, normalizing ferritin values and significantly decreasing erythropoietin consumption. ${ }^{36}$ According to Griveas, ${ }^{37}$ oral liposomal iron seems to be a safe and efficacious alternative in managing CKD patients with anemia. ${ }^{24}$

Other researchers suggest that therapy with two capsules of liposomal iron daily could be an alternative therapy in hemodialysis patients with iron deficiency. ${ }^{38}$ Arenas et $\mathrm{al}^{39}$ showed that liposomal iron was efficacious, well tolerated, and with an excellent therapeutic adherence treatment option for patients with nondialysis CKD. It is documented in one of the studies that addition of liposomal iron to the 12-week standard regimen with subcutaneous erythropoietin is effective in improving hematological parameters but also, more importantly, the QoL with no side effects and excellent tolerability in elderly anemic patients with no end-stage CKD. ${ }^{40}$ In anemic CKD patients at stages III to IV, supplementation with liposomal iron was associated with reduced activation of the inflammatory state, as assessed by reduction of erythrocyte sedimentation rate. ${ }^{41} \mathrm{It}$ is demonstrated that liposomal iron was safe and efficacious in maintaining transferrin saturation levels in peritoneal dialysis patients. Although ferritin levels decreased, they remained within therapeutic range. No gastrointestinal adverse effects were reported. ${ }^{42}$

\section{Celiac Disease}

Patients with celiac disease (CD) frequently suffer from IDA and may benefit from iron supplementation. After a follow-up of 90 days, CD and IDA patients in both liposomal and sulfate groups showed an increase in $\mathrm{Hb}$ levels compared with baseline $(+10.1$ and $+16.2 \%$ for liposomal and sulfate groups respectively), and a significant improvement in all iron parameters, with no statistical difference between the two groups. Therefore, liposomal iron can be effective in providing iron supplementation in difficult-to-treat populations. ${ }^{43}$

\section{Other Conditions}

It was demonstrated that liposomal iron was effective in replenishing iron storage in cirrhotic patients and despite the use of a high dose, it is well tolerated. ${ }^{44}$ In diabetic patients with IDA supported with liposomal iron, the need for median lispro insulin was lower than that of the patients supported with IV sodium ferrigluconate. ${ }^{32}$ Similarly, liposomal iron was found to be safe and costeffective in hepatitis $C$ virus patients with type II diabetes and anemia due to esophageal or gastric bleeding. ${ }^{45}$ In diabetic patients with IDA supported with liposomal iron, the median lispro insulin need appears to be lower than that of the patients supported with IV sodium ferrigluconate. However, the study needs confirmation on a larger cohort of patients. ${ }^{45}$

Researchers assessed the effect of switching to oral liposomal iron in patients receiving IV iron supplementation after bariatric surgery, which currently requires parenteral iron therapy due to intolerance to existing oral products or therapeutic failure. Oral liposomal iron was found be an excellent alternative to IV iron for maintenance treatment in bariatric surgery patients with iron deficiency. It might help to reduce health care costs and improve the QoL of these patients. ${ }^{24,46}$ Liposomal iron was found to be more effective and well tolerated than iron sulfate for correction of anemia in systemic sclerosis patients who have both chronic inflammation and gastrointestinal malabsorption issues. ${ }^{47}$ Liposomal iron therapy was found to be safe, well tolerated, and effective at least as a standard ferrous salt therapy in patients undergoing cytoreductive surgery with intraperitoneal hyperthermic chemotherapy. ${ }^{48}$

\section{COST-EFFECTIVENESS}

Scardino et $\mathrm{al}^{49}$ showed that liposomal iron was able to improve the preoperative protocol, allowing a shorter hospital stay and lower blood transfusions. Thus, liposomal iron supplementation is not only able to produce a faster $\mathrm{Hb}$ recovery after surgery, but it is able to decrease surgery-related cost. ${ }^{24}$ Simula, ${ }^{50}$ in his observation study, noted that in hematological ambulatory practice, oral supplementation with liposomal iron can be effective, safe, and preferred by patients to avoid IV therapy favoring QoL and, last but not least, it has a very low cost for public health. Similarly, liposomal iron was found to prevent the risks and reduce the costs of ESA treatment in elderly cancer patients. ${ }^{51}$ Though liposomal iron, compared with other oral formulations, is expensive, the cost of a dose of $30 \mathrm{mg}$ /day of liposomal pyrophosphate iron added to vitamin C $70 \mathrm{mg} /$ day is about 20 times less than the expense that a hospital facility has to face to administer intravenously a $62.5 \mathrm{mg}$ iron gluconate vial. ${ }^{14}$ Further, it is suggested by Scarpulla et $\mathrm{al}^{52}$ that liposomal iron can be considered an efficacious and tolerated alternative for the treatment of mild anemia in IBD patients. The effectiveness of this therapeutic approach is also associated with good compliance. 


\section{DOSAGE AND ADMINISTRATION}

Liposomal iron is available and the suggested dose is $30 \mathrm{mg} /$ day for 8 to 12 weeks, depending on the conditions. $^{21,26}$

\section{SAFETY PROFILE}

In general, oral supplementation of iron salts is often known to cause nausea, vomiting, epigastric discomfort, sensation of heaviness, and poor gastrointestinal tolerability. However, the distinguishing feature of liposomal iron has been evaluated in several studies and has shown to be devoid of common side effects of conventional oral iron supplementation, such as stomach pain, nausea, constipation, discoloration of the mucous, and feces. Moreover, data show that liposomal iron is better tolerated with few/absence of adverse effects and therefore, patients are more compliant. ${ }^{53}$

It is reported in the studies that about $30 \%$ of patients may experience adverse events with the nonliposomal oral iron, which can lead to dose reduction and/or nonadherence to the prescribed treatment, while adverse events occurred only in $3.1 \%$ of subjects on oral liposomal iron. ${ }^{54}$ In one comparative study, patients on oral liposomal iron had lower drug-related adverse event as compared with IV iron group (3.1 vs 34.5\%, p < 0.001). The most commonly experienced adverse events in the liposomal iron group were constipation (4.5\%) and diarrhea (4.5\%). No serious adverse effects were noted with liposomal iron. ${ }^{35}$ Similarly, in one of the studies, mild adverse effects like diarrhea, discoloration of stools, and constipation were noted with liposomal iron. ${ }^{48}$ However, several studies demonstrated no adverse effect of liposomal iron and that it was well tolerated.

The distinctive features of liposomal iron like high bioavailability, lesser side effects, and good compliance make it suitable to be used in patients who require iron administration and are intolerant to oral treatment, IV iron treatment, or lack good absorption.

\section{REFERENCES}

1. Barragán-lbañeza G, Santoyo-Sánchezb A, Ramos-PeñafielCO. Iron deficiency anaemia. Rev Méd Hosp Gen Méx 2016 Apr-Jun; 79(2):88-97.

2. Lopez A, Cacoub P, Macdougall IC, Peyrin-Biroulet L. Iron deficiency anaemia. Lancet 2016 Feb;387(10021):907-916.

3. Chellan R, Paul L. Prevalence of iron-deficiency anaemia in India: results from a large nationwide survey. JPSS 2010 Jul;19(1):59-80.

4. Camaschella C. Iron-deficiency anemia. N Engl J Med 2015 May;372(19):1832-1843.

5. De Franceschi L, Iolascon A, Taher A, Cappellini MD. Clinical management of iron deficiency anemia in adults: systemic review on advances in diagnosis and treatment. EJIM 2017 Jul;42:16-23.
6. Liu K, Kaffes AJ. Iron deficiency anaemia: a review of diagnosis, investigation and management. Eur J Gastroenterol Hepatol 2011 Feb;24(2):109-116.

7. Kaya Z. Iron deficiency anemia: current strategies for the diagnosis and management. Rev Health Care 2013;4(3):193-202.

8. Fei, C. Iron deficiency anemia: a guide to oral iron supplements. [cited 2018 Jun 29]. Available from: https://www. clinicalcorrelations.org/?p=8405. Accessed on June 29, 2018

9. Macdougall IC. Strategies for iron supplementation: oral versus intravenous. Kidney Int Suppl 1999 Mar;69(Suppl 69): S61-S66.

10. Jonathan BC, Jonathan B. Correcting iron deficiency. Aust Prescr 2016 Dec;39(6):193-199.

11. Zylberberg C, Matosevic S. Pharmaceutical liposomal drug delivery: a review of new delivery systems and a look at the regulatory landscape. Drug Deliv 2016 Nov;23(9):3319-3329.

12. Bulbake U, Doppalapudi S, Kommineni N, Khan W. Liposomal formulations in clinical use: an updated review. Pharmaceutics 2017 Mar;9(2):E12.

13. Mufamadi MS, Pillay V, Choonara YE, Du Toit LC, Modi G, Naidoo D, Ndesendo VM. A review on composite liposomal technologies for specialized drug delivery. J Drug Deliv 2011;2011:939851.

14. Visciano B, Nazzaro P, Tarantino G, Taddei A, Rio AD, Mozzillo GR, Riccio E, Capuano I, Pisani A. Il ferro liposomiale: una nuova proposta per il trattamento dell'anemia nell'insufficienza renale cronica. G Ital Nefrol 2013 Oct;30(5):1-9.

15. Paz, GB. Efficacy and tolerability of Sucrosomial ${ }^{\circledR}$ iron supplementation in IBD patients with iron deficiency anemia and intolerance to iron oral salts. 3rd Mediterranean Multidisciplinary Course on Iron Anemia, Rome, Italy, April 17-18, 2015.

16. Tarantino G, Elisa B, Zambito Y, Giordano G, Equitani F. Sucrosomial iron $^{\circledR}$ : a new highly bioavailable oral iron supplement. Blood 2015 Dec;126:4561.

17. Locatelli F, Mazzaferro S, Yee J. Iron therapy challenges for the treatment of nondialysis CKD patients. Clin J Am Soc Nephrol 2016 Jul;11(7):1269-1280.

18. Baomiao D, Xiangzhou Y, Li L, Hualin Y. Evaluation of iron transport from ferrous glycinate liposomes using Caco-2 cell model. Afri Health Sci 2017 Sep;17(3):933-941.

19. Ding B, Yi X, Li L, Yang H. Assessment of ferrous glycinate liposome absorption using in situ single-pass perfusion model. Int J Food Eng 2017 Aug;13(9):0358.

20. Mafodda A, Giuffrida D, Prestifilippo A, Azzarello D, Giannicola R, Mare M, Maisano R. Oral sucrosomial iron versus intravenous iron in anemic cancer patients without iron deficiency receiving darbepoetin alfa: a pilot study. Support Care Cancer 2017 Sep;25(9):2779-2786.

21. Prestifilippo A, Mafodda A, Maisano R, Giuffrida D, Mare M, Azzarello D, Blanco G, Nardi M. Safety and efficacy of oral liposomal iron supplemented in cancer patients with chemotherapy-related anemia receiving epoetin alfa: final data. ESMO Congress 2012, Viganello, Switzerland. 2012.

22. Barni S, Fausto P, Coinu A, Cabiddu M, Ghilardi M, Borgonovo $\mathrm{K}$, Lonati V. Up-front Sucrosomial ${ }^{\circledR}$ iron supplementation in patients with preexisting G1 anemia before planned chemotherapy: a prospective observational study. Exp Rev Hematol 2016;9(Suppl 1):1-42.

23. Monari F, Morganti AG, Frezza G, Dionisi V, Picchi SG, Rizzini EL. Oral Sucrosomial ${ }^{\circledR}$ iron (Sideral ${ }^{\circledR}$ Forte) supplementation in patients with advanced prostate cancer and bone metastasis treated with 223 radium dichloride. Exp Rev Hematol 2016;9(Suppl 1):1-42. 
24. Barni S. 4th mediterranean multidisciplinary course on iron anemia April 29th-30th 2016, Madrid, Spain. Exp Rev Hematol 2016 Sep;9(Suppl 1):1-42.

25. Romano A, Conticello C, Motta G, Caruso AL, Chiarenza A, Figuera A, Schinocca E, Consoli ML, Parisi M, Calafiore V, et al. Oral Sucrosomial ${ }^{\circledR}$ iron supplementation in patients affected by Hodgkin lymphoma with mild anemia before chemotherapy: an observational study. Exp Rev Hematol 2016;9(S1):1-42.

26. Indriolo A, Ravelli P. Comparison between liposomial iron and ferrous sulfate in patients with iron deficiency anemia and inflammatory bowel disease. A pilot controlled study. J Crohn's Colitis 2014 Feb;8(Suppl 1):S289.

27. Paz GB. Efficacy and tolerability of Sucrosomial ${ }^{\circledR}$ iron supplementation in IBD patients with iron deficiency anemia and intolerance to iron oral salts. Exp Rev Hematol 2016;9(Suppl 1): $1-42$.

28. Giordano G, Mondello P, Tambaro R, De Maria M, d'Amico F, Sticca G, di Falco C. Intravenous iron support or oral liposomal iron support in patients with refractory anemia treated with Epo alpha. Leuk Res 2011 May;35(Suppl 1):S137.

29. Giordano G, Mondello P, Tambaro R, Perrotta N, D'Amico F, D'Aveta A, Berardi G, Carabellese B, Patriarca A, Corbi GM, et al. Biosimilar epoetin $\alpha$ is as effective as originator epoetin- $\alpha$ plus liposomal iron $\left(\right.$ Sideral $^{\circledR}$ ), vitamin B12 and folates in patients with refractory anemia: a retrospective real-life approach. Mol Clin Oncol 2015 Jul;3(4):781-784.

30. Yu PP, Chang YZ, Yu P. Iron liposome: a more effective iron supplement for sports anemia and anemia of inflammation. J Pharma Care Health Sys 2015 Dec;S4:002.

31. Nasutia A, Sagristanib M, Sessa F. Oral Sucrosomial ${ }^{\circledR}$ iron (Sideral ${ }^{\circledR}$ Forte) is effective and well tolerated in elderly patients affected by iron deficiency anemia of various origins. Exp Rev Hematol 2016;9(Suppl 1):1-42.

32. Giordano G, D'Amico, D'Aveta, DeMaria M, Perrota N, Sansò C, Berardi G, Carabellese B. Sucrosomial iron better than iron sulfate in corrections of anemia of chronic inflammatory disease of young women. Italian Society of Hematology Congress. 2013.

33. Romano M. Sucrosomial ${ }^{\circledR}$ iron is effective in correcting inflammatory bowel disease anemia and is more tolerable than sulfate iron. Exp Rev Hematol 2016;9(Suppl 1):1-42.

34. Ralli C, Imperiali E, Tarantino G, Duranti E. Comparative study between Sideral forte and intravenous iron in chronic kidney disease. Exp Rev Hematol 2016;9(Suppl 1):1-42.

35. Pisani A, Riccio E, Sabbatini M, Andreucci M, Del Rio A, Visciano B. Effect of oral liposomal iron versus intravenous iron for treatment of iron deficiency anaemia in CKD patients: a randomized trial. Nephrol Dial Transplant 2015 Apr;30(4):645-652.

36. Pistoni, G.; Di Martino, M.; Veziano, E.; Saffioti, S. Effectiveness of Sucrosomial ${ }^{\circledR}$ Iron (Sideral ${ }^{\circledR}$ Forte) in dialysis patients in therapy with intravenous iron and erythropoietin (EPO). 57th Congress of Italian Society of Nephrology, Rome. 2016.

37. Griveas I. Effect of oral Sucrosomial ${ }^{\circledR}$ Iron in CKD patients with anemia. Poster Discussion. Exp Rev Hematol 2016;9(Suppl1): $1-42$.

38. Brunati C, Colussi G. Sucrosomial ${ }^{\circledR}$ Iron therapy in dialysis. Exp Rev Hematol 2016;9(Suppl 1):1-42.

39. Arenas MD, Herrera AC, Chacon A, Alzte E. Efficacy, tolerance, and adherence to treatment with Sucrosomial ${ }^{\circledR}$ Iron in patients with chronic kidney disease stages 3-4 and iron deficiency. Exp Rev Hematol 2016;9(Suppl 1):1-42.
40. Equitani F. Erythropoietin (EPO) plus oral Sucrosomial ${ }^{\circledR}$ Iron versus $\mathrm{EPO}$ alone for the treatment of severe anemia in no end-stage chronic kidney disease. Exp Rev Hemat 2016;9 (Suppl 1):1-42.

41. Altieri D, Geraci G, Mule G, Vario MG, Cottone S. Effects of oral Sucrosomial ${ }^{\circledR}$ Iron (Sideral ${ }^{\circledR}$ Forte) on inflammatory markers and endothelial dysfunction in CKD patients: preliminary data. Exp Rev Hematol 2016;9(Suppl 1):1-42.

42. Duarte V, Montoya A, Molina Y, Fulquet M, Esteve V, Pou M, Saurina A, MorenoF, Tapia I, de Arellano MR. OralSucrosomial ${ }^{\circledR}$ Iron in peritoneal dialysis patients. Exp Rev Hematol 2016; 9(Suppl 1):1-42.

43. Elli L, Ferretti F, Branchi F, Tomba C, Lombardo V, Scricciolo A, Doneda L, Roncoroni L. Sucrosomial iron supplementation in anemic patients with celiac disease not tolerating oral ferrous sulfate: a prospective study. Nutrients 2018 Mar;10(3):E330.

44. Vallerioa P, Stucchia M, Siricoa D, Buonoa A, Rinaldia I, Palazzinab M, Giannattasioa C. Sucrosomial ${ }^{\circledR}$ Iron and aortic stiffness in cirrhotic patients. Exp Rev Hematol 2016;9(Suppl 1): $1-42$.

45. Giodarno G, Parente A, Gigli R, Magri M, Berardi G, Carabellese B, d'Amico F, luciano I, Fratangelo R, Niro G, et al. Reduced insulin need in patients with type 2 diabetes mellitus (T2DM) with iron deficiency anemia treated with Sucrosomial ${ }^{\circledR}$ iron versus intravenous sodium ferrigluconate. Multicentric prospective study. Exp Rev Hematol 2016 Jun;9(Suppl 1):1-42.

46. Ciudin A, Simó-Servat O, Balibrea JM, Vilallonga R, Hernandez C, Simó R, Mesa J. Response to oral sucrosomial iron supplementation in patients undergoing bariatric surgery. The BARI-FER study. Endocrinol Diabetes Nutr 2018 Jan;65(1): 17-20.

47. Parisi S, Bruzzone M, Scarati M, Priora M, Peroni CL, Fusaro E. Efficacy of Sucrosomial ${ }^{\circledR}$ iron (Sideral ${ }^{\circledR}$ Forte) in the treatment of anemia in patients affected by systemic sclerosis. Exp Rev Hematol 2016;9(Suppl 1):1-42.

48. Barragans M, Camblor M, Cuerda C, Bretóna I, Motillaa M, Carrascala L, Velascoa C, Higueraa I, Vasquezb W, GonzalezBayón L, et al. Sucrosomial ${ }^{\circledR}$ iron versus ferrous sulfate for anemia in patients undergoing peritoneal carcinomatosis with cytoreductive surgery and hyperthermic intraperitoneal chemotherapy. Exp Rev Hematol 2016;9(Suppl 1):1-42.

49. Scardino M, D'Amto T, Martorelli F, Fenocchio G, Pera E, Tarantino G. A cost-effective implementation of preoperative protocol with Sucrosomial ${ }^{\circledR}$ iron supplementation. Blood 2017 Dec;130(Suppl 1):3352.

50. Simula F. Effectiveness of Sucrosomial ${ }^{\circledR}$ iron in ambulatory patients. Exp Rev Hematol 2016;9(Suppl 1):1-42.

51. Grillone F, Gualtieri S, Ventura M, Costantino N, Tassone P, Tagliaferri P. Efficacy and tolerability of Sucrosomial ${ }^{\circledR}$ iron in elderly ( $\geq 75$ years) patients with solid tumors treated with anticancer agents: a retrospective analysis. Exp Rev Hematol 2016;9(Suppl 1):1-42.

52. Scarpulla G, Garufi S, La Ferrera G, Manganaro M, Scalisi G, Cammilleri S. Effectiveness and compliance of oral Sucrosomial ${ }^{\circledR}$ Iron (Sideral ${ }^{\circledR}$ Forte) in asymptomatic inflammatory bowel disease. Exp Rev Hematol 2016;9(Suppl 1):1-42.

53. Barzaghi D, Olga C, Massimo E, et al. Sucrosomial ${ }^{\circledR}$ iron and radiotherapy in the neoadjuvant treatment of rectal cancers. Good news for patients? Exp Rev Hematol 2016;9(Suppl 1):1-42.

54. Charytan C, Quinbi W, Bailie GR; Venofer Clinical Studies Group. Comparison of intravenous iron sucrose to oral iron in the treatment of anemic patients with chronic kidney disease not on dialysis. Nephron Clin Pract 2005 Apr;100(3):c55-c62. 